\title{
Representativeness of total column water vapour retrievals from instruments on polar orbiting satellites
}

\author{
Hannes Diedrich, Falco Wittchen, René Preusker, and Jürgen Fischer \\ Institut für Weltraumwissenchaften, Freie Universität Berlin, Carl-Heinrich-Becker-Weg 6-10, 12165 Berlin, Germany \\ Correspondence to: Hannes Diedrich (hannes.diedrich@gfz-potsdam.de)
}

Received: 1 February 2016 - Published in Atmos. Chem. Phys. Discuss.: 26 April 2016

Revised: 22 June 2016 - Accepted: 24 June 2016 - Published: 11 July 2016

\begin{abstract}
The remote sensing of total column water vapour (TCWV) from polar orbiting, sun-synchronous satellite spectrometers such as the Medium Resolution Imaging Spectrometer (MERIS) on board of ENVISAT and the Moderate Imaging Spectroradiometer (MODIS) on board of Aqua and Terra enables observations on a high spatial resolution and a high accuracy over land surfaces. The observations serve studies about small-scale variations of water vapour as well as the detection of local and global trends. However, depending on the swath width of the sensor, the temporal sampling is low and the observations of TCWV are limited to cloud-free land scenes.

This study quantifies the representativeness of a single TCWV observation at the time of the satellite overpass under cloud-free conditions by investigating the diurnal cycle of TCWV using 9 years of a 2-hourly TCWV data set from global GNSS (Global Navigation Satellite Systems) stations. It turns out that the TCWV observed at 10:30 local time (LT) is generally lower than the daily mean TCWV by $0.65 \mathrm{~mm}$ (4\%) on average for cloud-free cases. Averaging over all GNSS stations, the monthly mean TCWV at 10:30 LT, constrained to cases that are cloud-free, is $5 \mathrm{~mm}(25 \%)$ lower than the monthly mean TCWV at 10:30 LT of all cases. Additionally, the diurnal variability of TCWV is assessed. For the majority of GNSS stations, the amplitude of the averaged diurnal cycle ranges between 1 and $5 \%$ of the daily mean with a minimum between 06:00 and 10:00 LT and maximum between 16:00 and 20:00 LT. However, a high variability of TCWV on an individual day is detected. On average, the TCWV standard deviation is about $15 \%$ regarding the daily mean.
\end{abstract}

\section{Introduction}

Water vapour plays a key role in the hydrological cycle of the earth's atmosphere. The total column water vapour (TCWV) is a good indicator and/or tracer of atmospheric transport of water vapour. The diurnal cycle of TCWV over land is influenced by evapotranspiration as a source, condensation and precipitation as sinks, and additionally by atmospheric advection (Trenberth, 1999). Over the years, multiple techniques have been established to determine the TCWV from ground and from space. TCWV from measurements of radiosondes, microwave radiometers and Global Navigation Satellite Systems (GNSS) receivers are examples for sophisticated ground-based sources of TCWV values on a high temporal resolution that are hardly affected by clouds (e.g. RS: Seidel et al., 2009, MWR: Turner et al., 2007, GNSS: Dick et al., 2001). Unfortunately, the ground-based measurements do not resolve the spatial structures of water vapour fields. Further, they are usually limited to land areas. However, satellite remote sensing allows observations of TCWV on a high spatial resolution. Over land surfaces, TCWV derived from radiance measurements in the near-infrared (NIR) from space-borne spectrometers meets the requirement needed for weather forecasts and climate studies, due to high accuracy and high spatial resolution (up to $300 \mathrm{~m}$ ) of the TCWV products. Observations from the MEdium Resolution Imaging Spectrometer (MERIS) (Bennartz and Fischer, 2001; Lindstrot et al., 2012) on ENVISAT and the Moderate Resolution Imaging Spectroradiometer (MODIS) on Aqua and Terra (Gao and Kaufman, 2003; Diedrich et al., 2015) can provide long time series of TCWV. These data sets, such as those described by Lindstrot et al. (2014), benefit global trend analysis or investigations of small-scale phenomena as described by Carbajal Henken et al. (2015). However, there 
are two major drawbacks of observations by polar orbiting satellites:

- Most areas are sampled only once per day or even less depending on the latitude and the swath width of the instrument.

- Clouds are opaque in the visible and NIR spectrum. Consequently, the observations of TCWV are limited to cloud-free areas.

For the observation of the diurnal variability of TCWV ground-based microwave radiometer and GNSS measurements are appropriate. The influence of clouds and precipitation can be neglected for GNSS observations. TCWV can be derived from measurements of the zenith path delay (ZPD) of ground-based GNSS receivers even under cloudy conditions and on temporal resolutions up to a few minutes. Nine years of 2-hourly TCWV data derived from GNSS measurements have been used in order to answer the following questions:

1. How large is the variability of the TCWV in comparison to the daily mean TCWV?

2. How representative is the TCWV at the time of the satellite overpass to the daily mean TCWV?

3. How representative is the climatology of the cloudfree TCWV to the TCWV climatology including cloudy conditions at the time of the satellite overpass?

There are few studies that examine the diurnal cycle of water vapour such as Li et al. (2007), Ortiz de Galisteo et al. (2011) and Radhakrishna et al. (2015). However, these works usually focus on certain regions. In this study we would like to highlight the potential of a global TCWV data set and present a global analysis of the diurnal cycle of TCWV. We want to give an overview of the variability of TCWV that is needed for the interpretation of water vapour fields derived from remote sensing.

\section{Satellite TCWV data sets}

As mentioned above, the daily coverage of imaging spectrometers on sun-synchronous polar orbiting satellites is limited by the field of view of the specific instrument. MERIS on ENVISAT has a swath width of $1150 \mathrm{~km}$ which leads to global coverage in about 2-3 days. MODIS on Terra scans the earth in 1-2 days with a swath width of $2330 \mathrm{~km}$. Consequently, in the lower latitudes observations take place only once every 3 days; in the middle latitudes they take place about once per day. Information about the daily cycle of TCWV can not be retrieved from this kind of observations. However, climate monitoring requires trend analysis which is performed with the aid of TCWV from space-borne spectrometers due to the global coverage. ENVISAT and Terra cross the equator at about 10:30 a.m. local time, both at descending note. TCWV retrievals that are based on radiance measurements in the NIR (Diedrich et al., 2015; Lindstrot et al., 2012) are limited to cloud-free areas where high accuracies can only be provided over land surfaces (Diedrich et al., 2013).

\section{GNSS TCWV data set}

The basis of our investigation is a 2-hourly TCWV data set from Wang et al. (2007) for the years 2003 to 2011. The TCWV was derived from ground-based GNSS measurements of zenith path delay (ZPD) using three different resources, including the International GNSS (Global Navigation Satellite Systems) Service (IGS) tropospheric products, U.S. SuomiNet (UCAR/COSMIC) products and Japanese GEONET (GNSS Earth Observation Network) data (Earth Observing Laboratory, 2011). All GNSS TCWV retrievals are based on the same procedure, explained shortly in the following section. The TCWV is derived from the delay of the GNSS signal that is introduced by interactions with the atmosphere. By subtracting the ionospheric and hydrostatic attenuation, and accounting for the elevation angle of the satellites, the zenith wet delay (ZWD) can be approximated, that is in the range of a few centimetres (Bevis et al., 1992). Subsequently, the ZWD is converted to TCWV. Although there are a number of error influences, the uncertainty of TCWV derived from GNSS is about 1-2 mm (Ning et al., 2016).

TCWV observations from about 1000 global distributed stations for the period between 1995 to 2011 are available in the data set. However, the majority of stations do not contribute continuously over the whole time and the number of stations increases with time. In order to have a relatively complete time series of TCWV for each station, we selected only locations that provided at least 5 years of data in the period of 2003 and 2011. Figure 1 shows the spatial distribution and the elevation of the selected 296 stations. There is a high density in Europe and the USA and only a few stations in South America, Africa and Central Asia. Nevertheless, the spectrum of the locations is diverse. The stations are located in very dry and humid conditions at continental and coastal locations range from sea level to $3600 \mathrm{~m}$. Besides other influences, the diurnal cycle of water vapour in the lower troposphere is hypothetically linked to the diurnal cycle of temperature that is in turn mainly driven by the position of the sun. Therefore, we converted the time information in the GNSS data set (given in UTC) to the local time (LT) that is used hereafter and is derived as follows:

$\mathrm{LT}=\mathrm{UTC}+(\varphi / 15), \varphi \in\{-180, \ldots, 180\}$,

where $\varphi$ is the longitude of the location of the corresponding station. 

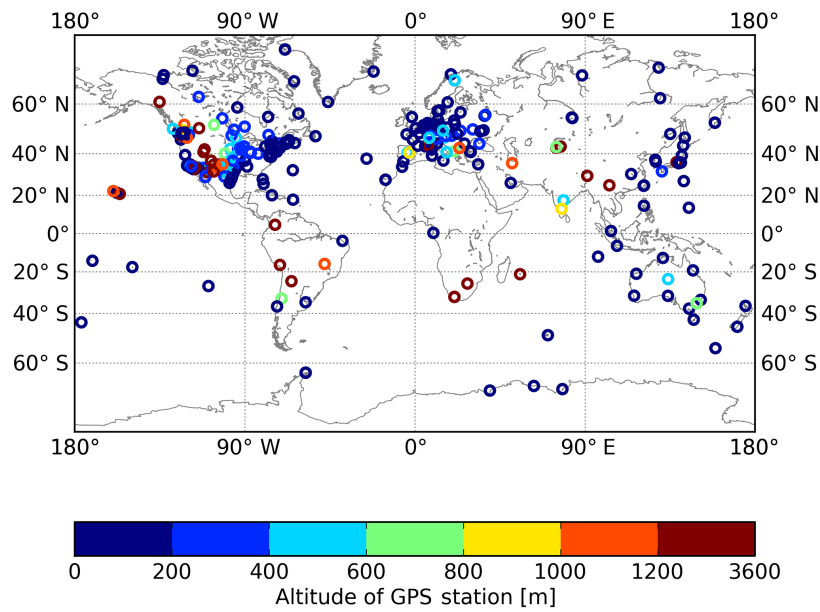

Figure 1. Global distribution and height in metres of selected GNSS stations. Note that the last height class contains all stations between $1200 \mathrm{~m}$ and $3600 \mathrm{~m}$ elevation.

\section{Diurnal cycle of TCWV}

The main part of the column integrated water vapour is located in the boundary layer. Consequently, TCWV can represent the processes related to water vapour that take place in the lower troposphere. There are several mechanisms that influence the TCWV. The most important ones are the following: evaporation and condensation, large-scale and local advection of moist or dry air. Considering averages over a large number of days, the large-scale advective part is usually represented at all times of a day, leaving only the variations that are connected to the diurnal cycle in air temperature. With increasing surface temperature over the day, the evaporation can increase. At night water vapour condensates and consequently, TCWV decreases on average. Another influence is the advection of humid or dry air masses. Winds originate from synoptic situations or orographic circumstances. The wind is generally higher at daytime because of convection that in turn will also influence the water vapour amount. Local geographic conditions can result in circulation patterns that occur almost every day such as land and sea breeze and mountain breeze. The differential warming between land and ocean carries moisture onshore at daytime. At night-time this circulation is reversed due to the faster cooling of the land surfaces. The climatic and geographic conditions are various for the selected stations. In some cases, these influences are dependent on the time of the year due to the annual variability of the circulation pattern. To analyse every single station concerning its diurnal cycle would exceed the frame of this paper. Consequently, a statistical approach of the evaluation of the diurnal cycle is presented in the following section.

An evaluation of the diurnal variability of the TCWV anomaly from the daily mean for the 296 considered stations averaged over 9 years (2003-2011) is represented in Fig. 2

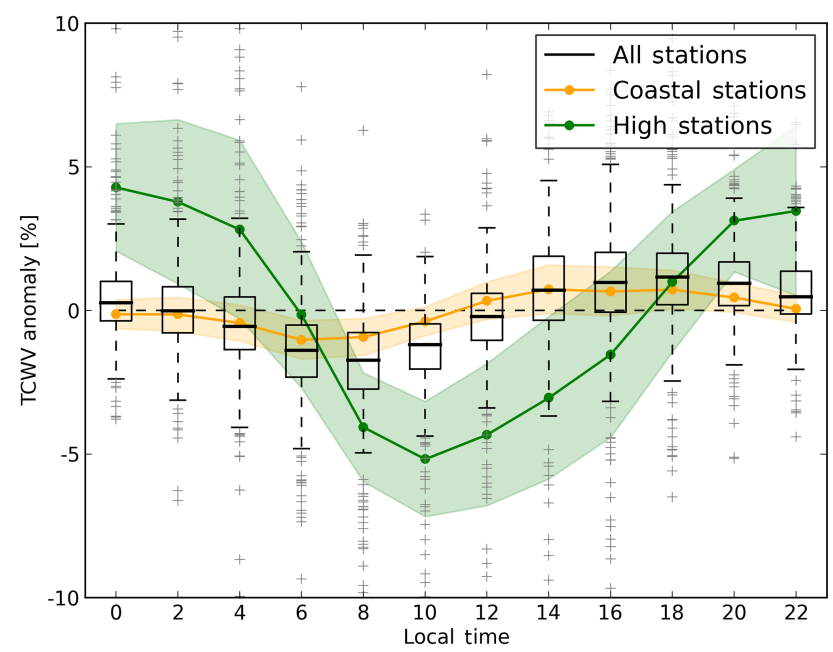

Figure 2. Boxplot of TCWV anomalies from the daily mean in percentage for all stations and the period between 2003 and 2011. The range of the black boxes indicates the interquartile range (IQR), containing $50 \%$ of the data points (each point represents one stations). The horizontal bar within the boxes represents the median; vertical bars (whiskers) indicate the reach of $95 \%$ of the data points; and grey pluses show outliers. Green line: mean daily cycle of TCWV of all high stations (greater than $800 \mathrm{~m}$ altitude); orange line: Mean daily cycle of TCWV for coastal stations. See text for detailed description.

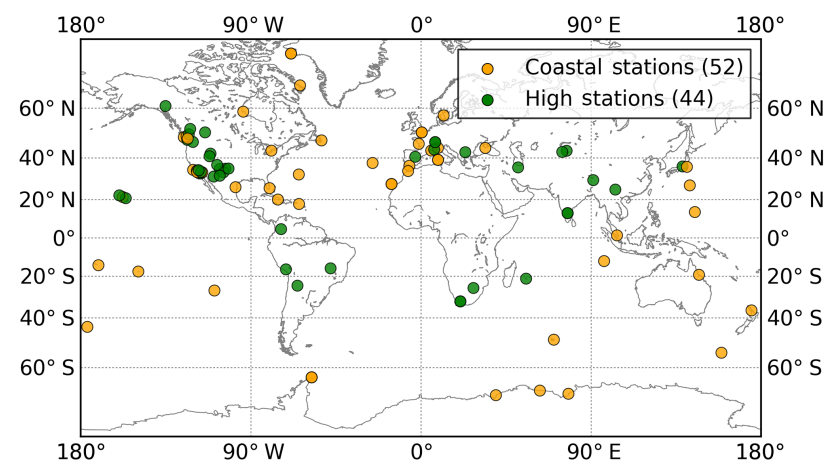

Figure 3. Location of the stations that were selected for coastal (orange) and high stations (green).

as box plot. Black boxes and whiskers indicate a histogram of the TCWV anomaly including all stations for each 2-hour time step. The inner-quartile range (IQR) varies between +2 and $-2 \%$ of the daily mean TCWV (indicated by the horizontal dashed line). There is a significant minimum of the station median TCWV (indicated by the horizontal bar in the boxes) between 06:00 and 10:00 LT and a maximum between 16:00 and 20:00 LT with an amplitude of about 1\%. TCWV at $95 \%$ of the stations varies between -5 and $+5 \%$.

In order to analyse the influence of the location to the averaged daily cycle of TCWV, two subgroups of stations are selected: 52 coastal stations that are situated within $5 \mathrm{~km}$ of 

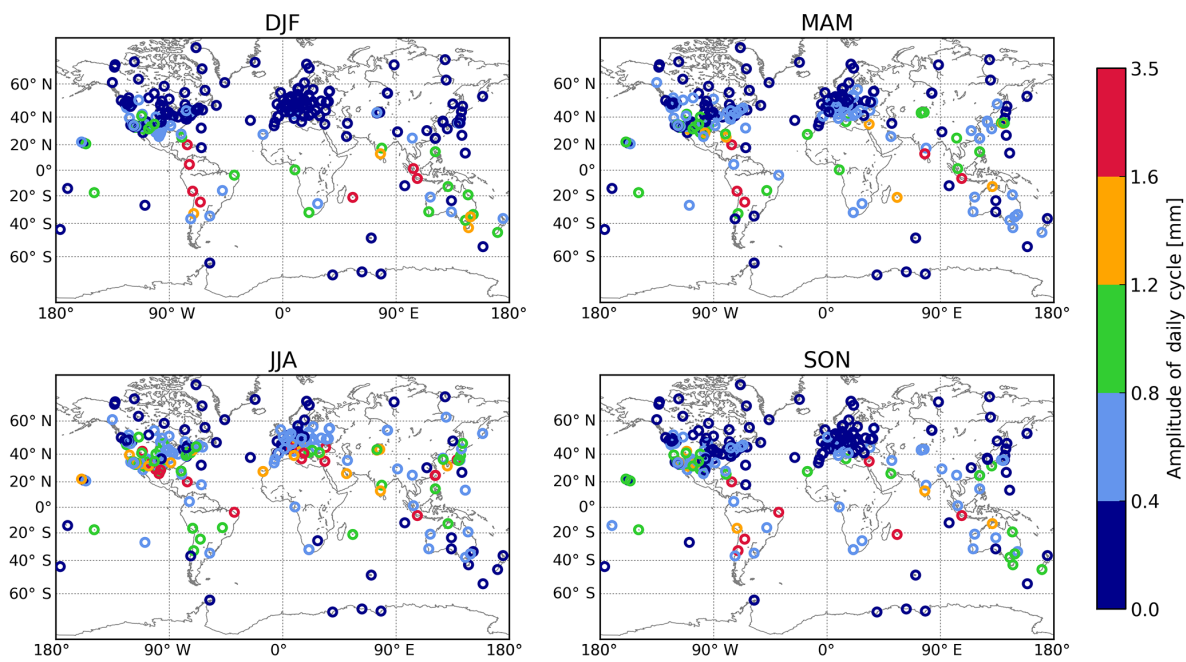

Figure 4. Season-averaged amplitude of the daily cycle of TCWV for each GNSS station in millimetres.
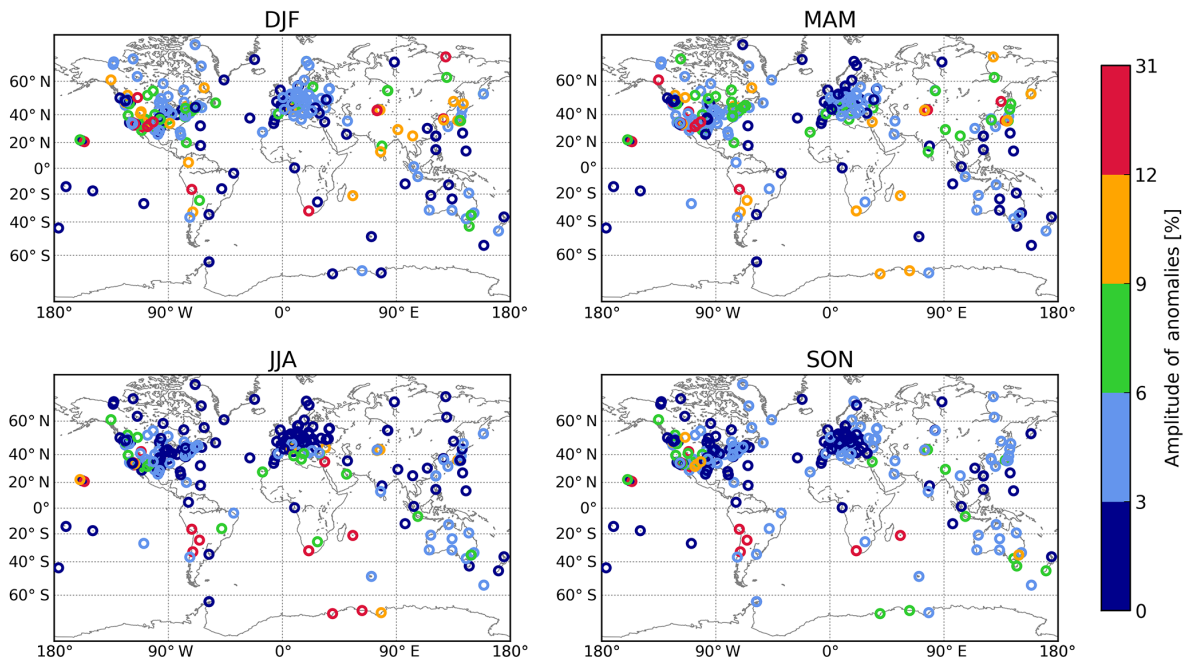

Figure 5. Season-averaged amplitude relative to the daily cycle of TCWV for each GNSS station in percentage.

a coast of the ocean or large lakes and below $800 \mathrm{~m}$ elevation (indicated orange in Figs. 2 and 3), and 44 high GNSS stations that are situated above $800 \mathrm{~m}$ (indicated green). The coloured lines in Fig. 2 show the mean diurnal TCWV anomaly of the two groups including the range of the standard deviation as coloured shading. The diurnal variability of the high stations is most pronounced in this comparison, peaking at 00:00 and 10:00 LT with an amplitude of about $5 \%$. The reasons for this particular shape could be manifold depending on, e.g. the local circumstances of the terrain and availability of humidity. A possible explanation for the large amplitude of the diurnal cycle of TCWV anomalies could be the larger daily variation of air temperature in mountain areas resulting from enhanced warming of the slopes at daytime and enhanced cooling at night due to the higher surface area. In order to find out the true reasons of the different di- urnal cycles of high stations, other data have to be taken into account, such as air temperature.

The diurnal mean TCWV anomaly of coastal stations is following the overall mean TCWV anomaly of about $1 \%$. Here, the sea breeze could be an explanation for the peak times. The flow of humid air from the ocean is maximal in the afternoon and minimal in the morning. The relative amplitude of the diurnal cycle of TCWV is low in comparison to other stations presumably because of the general high humidity at the coast.

The variation of the averaged diurnal cycle of TCWV anomalies between the high stations is larger than between the coastal stations, represented by the standard deviation. This potentially results from the large variation of locations of the high stations. 

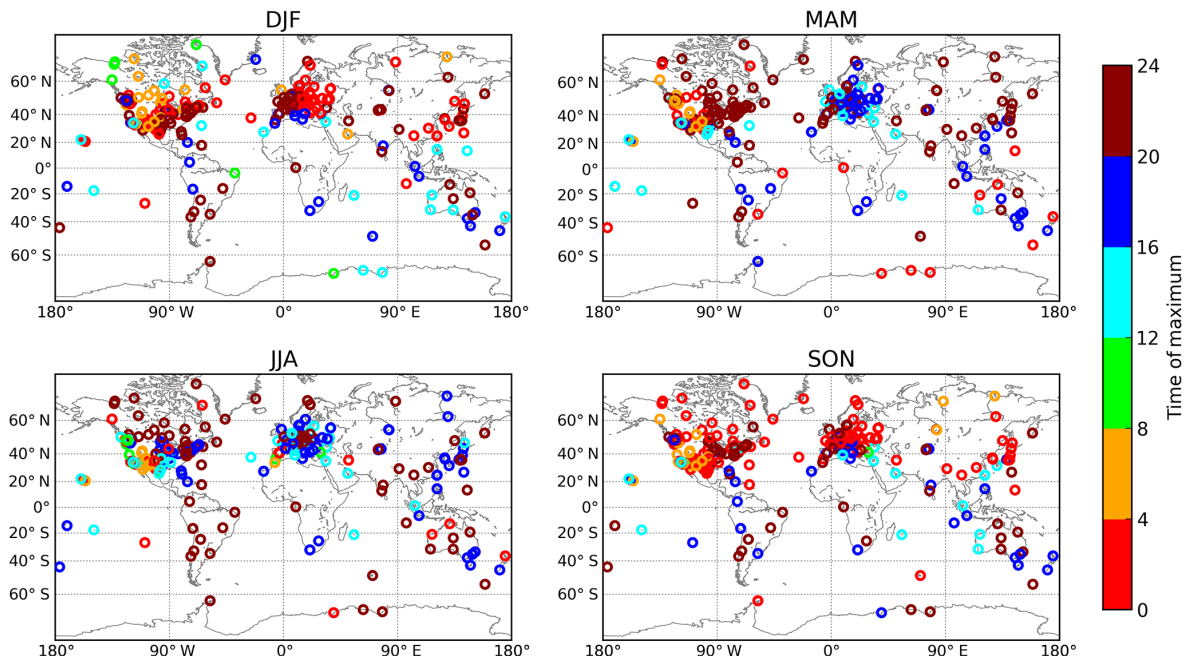

Figure 6. Local time of occurrence of the maximum of the seasonal-averaged daily cycle.
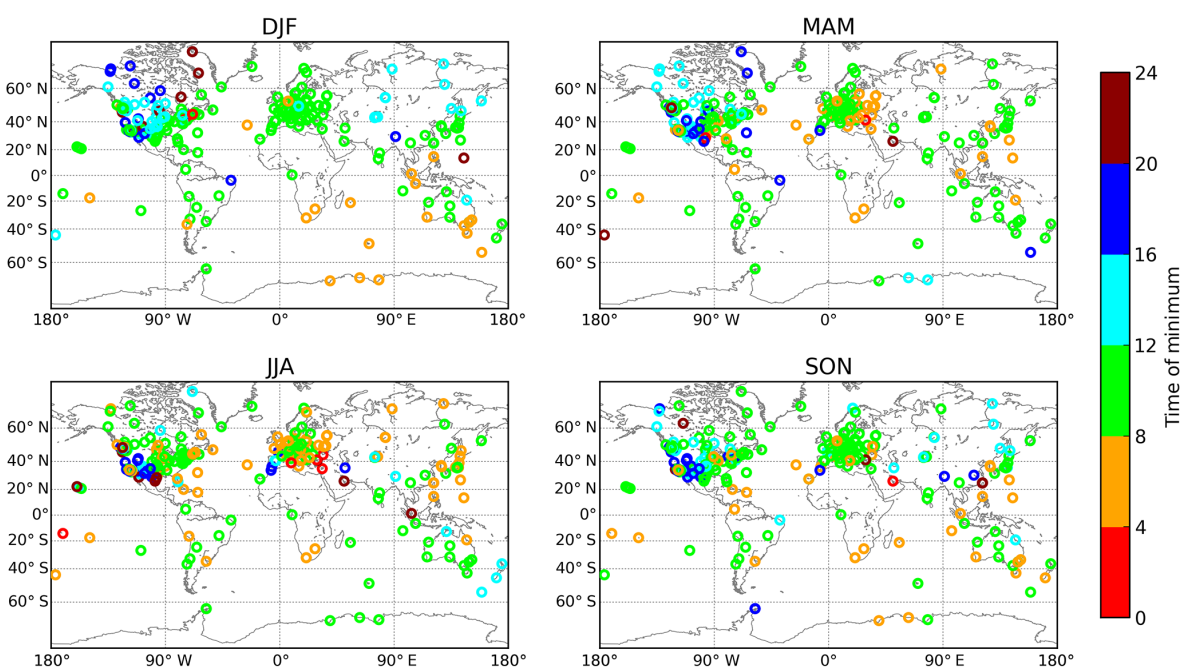

Figure 7. Local time of occurrence of the minimum of the seasonal-averaged daily cycle.

In order to get the global view on the averaged daily variability of TCWV we derived measures that indicate the shape and amplitude of the mean diurnal cycle of each GNSS station. In Fig. 4 the season-averaged amplitude, meaning the difference between the maximal TCWV and the daily mean TCWV, of the daily cycle of TCWV is plotted for each station. The first obvious feature is that the amplitude of the diurnal cycle is increasing with decreasing latitude and the maximum of the zonal mean amplitude is moving north in northern summer and south in northern winter. This can be explained by the annual variation of the lower tropospheric temperature. Furthermore, the amplitude ranges from 0.1 to $0.8 \mathrm{~mm}$ in the middle and high latitude to $3.5 \mathrm{~mm}$ for stations in the tropics and mid-west of the USA. Considering the potential range of TCWV in the atmosphere between 1 and $70 \mathrm{~mm}$ this range seams rather low. In order to study how much the daily cycle constitutes to the daily mean TCWV, the anomalies from the daily mean are presented in Fig. 5, averaged again over the seasons. It shows that for most of the stations the daily variability is only in the range of $1-5 \%$. For most of the stations with higher altitudes the anomalies are increased and range up to $31 \%$ that is consistent with the findings in Fig. 2. In general, the amplitude of the daily anomalies does not follow the global temperature distribution.

Another interesting feature of the diurnal cycle of TCWV is the time when the TCWV reaches its maximum or minimum. In Figs. 6 and 7 the local time when the stationaveraged daily cycle of TCWV reaches the maximum and minimum respectively is shown for every season. At the majority of the stations a similar shape of the diurnal cycle appears resulting in the same times of the maximum and the 


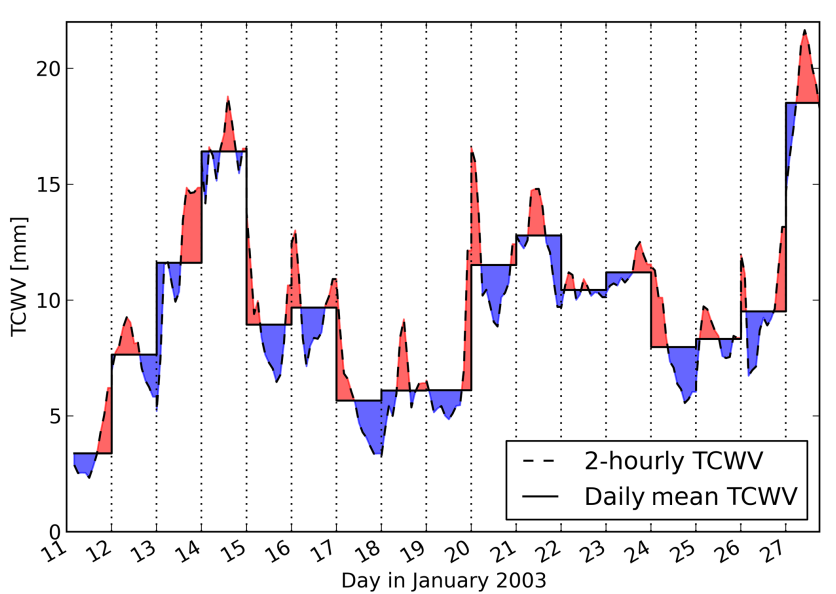

Figure 8. GNSS TCWV for 16 days in January 2003 at the station Potsdam (POTS) in blue. Daily average TCWV in black. Anomalies are coloured (positive: red, negative:blue).

minimum in each season. This is demonstrated by the dominating reddish and blue colours on the maximum plot and dominating green and orange colours in the minimum plot. It leads to a mean daily TCWV variation that is minimal in the morning between 04:00 and 12:00 LT and that is maximal at night between 16:00 and 04:00 LT that again is consistent with the mean daily cycle for all stations in Fig. 2. However, there are stations with different characters, e.g. in the Rocky Mountains that peak between 04:00 and 08:00 LT for the maximum and between 16:00 and 20:00 LT for the minimum. This shape is reverse to the other stations. At the ENVISAT and Terra overpass the average TCWV for the majority of stations is still slightly below the daily mean. This is the main reason for the negative bias between the TCWV derived at 10:30 LT and the daily mean (next section).

In general, the variation of the averaged diurnal cycle of TCWV between the stations is large concerning the time of the maximum or minimum and the amplitude and is mainly dependent on the location of the GNSS station. This is consistent with Fig. 2, where the spread of the standard deviations, boxes and whiskers indicate that the averaged diurnal cycle varies by more than $\pm 10 \%$ between the stations. The averaged amplitude is only in the range of a few percent of the mean TCWV.

However, this information does not quantify the individual daily variability of the TCWV. Figure 8 shows the TCWV for 16 days in January 2003 for the GNSS station Potsdam as dashed line. Additionally, the daily mean TCWV is plotted. For better visibility, the positive difference between the curves are coloured red and the negative areas are coloured blue. The comparison reveals that the daily cycle of TCWV is different for every day. In order to quantify this variability, the daily standard deviation (DSD) of the TCWV as anomaly from the daily mean, averaged for each station is plotted on the right panel in Fig. 9 as frequency density plot. The DSD for each station ranges between 5 and $35 \%$. The median is at $15.1 \%$ (equivalent to $2 \mathrm{~mm}$ TCWV; indicated by the dashed vertical line) and $80 \%$ of the stations show a DSD between 11 and $21 \%$ (indicated by the green colour). Additionally, the location of the percentile groups is plotted in the left panel of Fig. 9. GNSS stations with low DSD (10th percentile; indicated blue) are generally distributed in the tropical region. This region is known to have a low daily variability of temperature and humidity. The outliers with high DSD (red) are not limited to special climatological regions.

In summary, the averaged anomaly of the daily mean TCWV varies only between 1 and $5 \%$ for the majority of stations. This is important information for the interpretation of climatologies of TCWV from observations of polar orbiting satellites (see next chapter). However, the variability around the daily mean for an individual day is significantly higher, on average up to $35 \%$.

\section{Representativeness of TCWV at 10:30 LT to daily mean TCWV}

Whether one observation at the overpass time of the satellite is representative for the daily mean TCWV was investigated. The bias between the TCWV (observed at 10:30 LT) and the daily mean TCWV (for all days that were cloud-free at 10:30 LT) was averaged for each GNSS station and shown in Fig. 10. Cloud information was extracted from the operational MERIS cloud mask. For the investigation in this and the next chapter, the corresponding MERIS pixel was spatially collocated for each GNSS observation. The right plot represents the distribution of frequency of the bias for each station. Blue bars indicate the bias classes that are within the 10th percentile of the distribution and red bars above the 90th percentile. The spatial distribution of the GNSS stations is shown in the left plot. A negative bias indicates that the 10:30 LT TCWV is lower than the daily mean. Here, the number of considered stations is reduced to 202 because some stations were mostly cloud covered at 10:30 LT. Figure 10 shows a station-mean bias of $-0.63 \mathrm{~mm}$ (illustrated by the vertical dashed line in the histogram) that is within the measurement accuracy of the GNSS measurements and within the uncertainty ranges of a typical TCWV retrieval from observations in the NIR (Diedrich et al., 2013). The station with low biases are distributed in the tropical region, where the variability of TCWV is smaller than in other regions. In general, negative biases appear at nearly all stations. This is consistent with the findings of the last chapter, where the averaged anomaly of the diurnal cycle of TCWV is negative at 10:30 LT. 

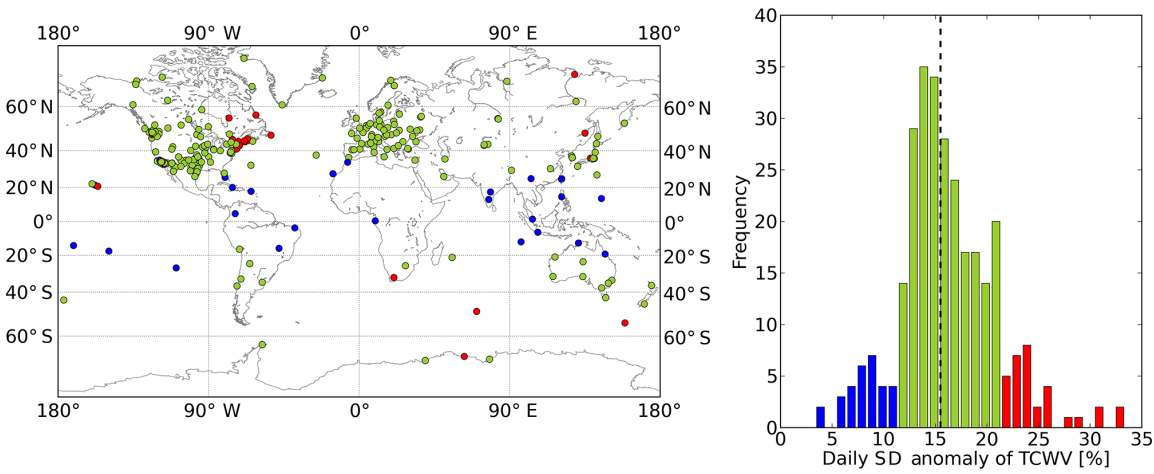

Figure 9. Mean daily standard deviation (DSD) anomaly from the daily mean TCWV in percentage. Right plot: histogram of the DSD, blue bars indicate the classes that are in the 10th percentile, red bars indicate classes that are above the 90th percentile; the vertical dashed line illustrates the position of the station-median standard deviation anomaly. Left plot: spatial distribution of stations coloured in the three percentile classes.
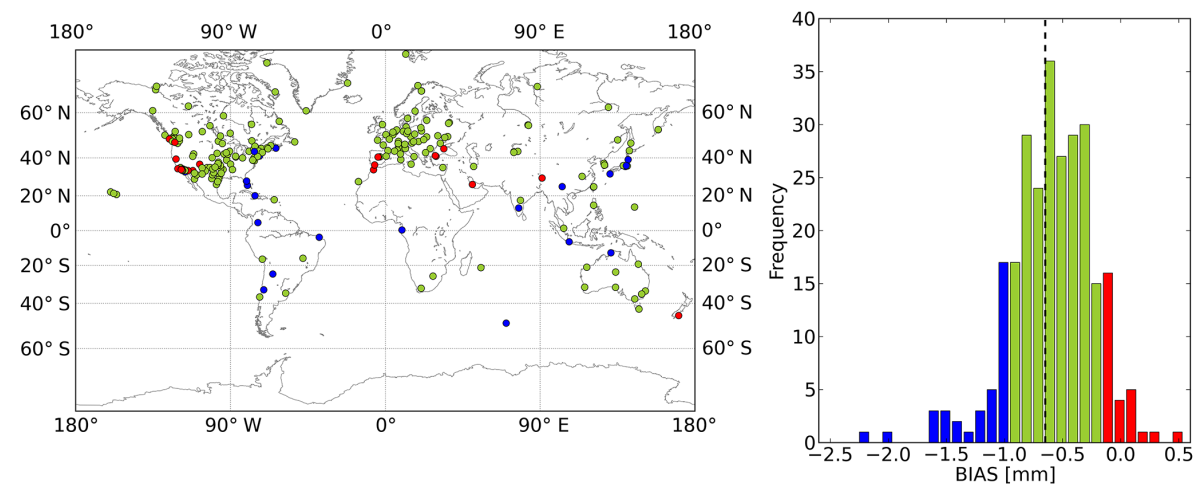

Figure 10. Bias for each station between the TCWV observed at 10:30 LT and the daily mean TCVW for all cases, that were cloud-free at 10:30 local time. Right plot: histogram of the bias, blue bars indicate the classes that are in the 10th percentile, red bars indicate classes that are above the 90th percentile; the vertical dashed line illustrates the position of the station-median bias. Left plot: spatial distribution of stations coloured with the three percentile classes.

\section{Representativeness of cloud-free monthly-mean TCWV to monthly-mean TCWV at 10:30 LT}

The fact that TCWV derived from instruments like MERIS and MODIS is limited to cloud-free areas has to be considered in the interpretation of trend analysis. Figure 11 shows monthly mean TCWV derived at 10:30 LT of all considered GNSS stations for the period 2003-2011 in blue including all cases and cloud-free cases in red. There is a clear difference in TCWV between all cases and non-cloudy cases. On average, TCWV is about $25 \%(5 \mathrm{~mm})$ higher for all scenes than for clear scenes. This increase in TCWV for cloudy cases has been detected also in the study by Gaffen and Elliott (1993). Concerning climatological studies of absolute TCWV values, the TCWV observed at cloud-free cases is not representative for the TCWV including all cases. Nevertheless, the cloud-free and all-case TCWV are highly correlated.

\section{Conclusions}

In this investigation the representativeness of the TCWV derived from imaging spectrometers that measure radiance in the NIR on polar orbiting satellites is discussed. A TCWV data set derived from GNSS delay measurements that is hardly influenced by clouds has been used. It turns out that on average the TCWV observed at 10:30 LT on cloud-free cases is generally lower than the daily mean TCWV. The bias of $-0.65 \mathrm{~mm}(-4 \%)$ is in the range of the mean amplitude of the diurnal cycle. The monthly mean TCWV observed at 10:30 LT constrained to cloud-free cases is significantly lower than the monthly mean TCWV of all cases by about $25 \%(5 \mathrm{~mm})$. Nevertheless, the diurnal cycle is only a few percent of the daily mean TCWV for most of the stations. On average, for the majority of stations TCWV peaks at the evening and is minimal in the early morning local time. However, the variability on an individual day is much higher. The daily standard deviation averaged for every station is about 


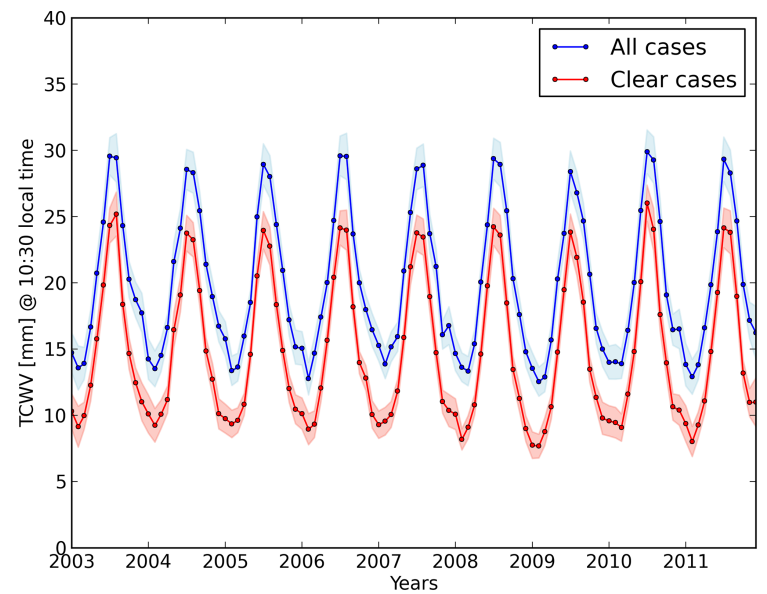

Figure 11. Monthly mean TCWV of all selected stations for cloudy scenes in blue and non-cloudy scenes in red lines.The shading indicates the $95 \%$ significance interval.

$15 \%$ of the daily mean. In summary, the biggest influence on the representativeness of observed TCWV from polar orbiting satellites is the constraint to cloud-free areas. The time of observation is a minor factor and, in case of the MODIS and MERIS overpass, negligible when averaging over time. The used GNSS-TCWV data set, collocated with cloud information data from satellites, offers a lot of potential for studies concerning, for example, the interaction between clouds and water vapour. As precipitation also strongly influences the water transport and consequently TCWV, the collocation of rain gauge data can also serve a more detailed view of the reasons for the individual diurnal viability of TCWV.

\section{Data availability}

A 2-hourly TCWV data set from Wang et al. (2007) was used (explained in detail in Sect. 3; accessible on: Earth Observing Laboratory, 2011).

Acknowledgements. This study was performed in the framework of the BMWi project WaDaMo and supported by ESA (European Space Agency) project SEOM (Scientific Exploitation of Operational Missions). The authors would like to thank Galina Dick from GFZ (Geoforschungszentrum) Potsdam for the input concerning GNSS TCWV retrievals and interpretation.

Edited by: S. Buehler

Reviewed by: two anonymous referees

\section{References}

Bennartz, R. and Fischer, J.: Retrieval of columnar water vapour over land from backscattered solar radiation using the Medium Resolution Imaging Spectrometer, Remote Sens. Environ., 78, 274-283, doi:10.1016/S0034-4257(01)00218-8, 2001.

Bevis, M., Businger, S., Herring, T. A., Rocken, C., Anthes, R. A., and Ware, R. H.: GPS meteorology: Remote sensing of atmospheric water vapor using the global positioning system, J. Geophys. Res., 97, 15787, doi:10.1029/92jd01517, 1992.

Carbajal Henken, C. K., Diedrich, H., Preusker, R., and Fischer, J.: MERIS full-resolution total column water vapor: observing horizontal convective rolls, Geophys. Res. Lett., 42, 10074-10081, doi:10.1002/2015g1066650, 2015.

Dick, G., Gendt, G., and Reigber, C.: First experience with near real-time water vapor estimation in a German GPS network, J. Atmos. Sol.-Terr. Phy., 63, 1295-1304, doi:10.1016/S13646826(00)00248-0, 2001.

Diedrich, H., Preusker, R., Lindstrot, R., and Fischer, J.: Quantification of uncertainties of water vapour column retrievals using future instruments, Atmos. Meas. Tech., 6, 359-370, doi:10.5194/amt-6-359-2013, 2013.

Diedrich, H., Preusker, R., Lindstrot, R., and Fischer, J.: Retrieval of daytime total columnar water vapour from MODIS measurements over land surfaces, Atmos. Meas. Tech., 8, 823-836, doi:10.5194/amt-8-823-2015, 2015.

Earth Observing Laboratory: National Center for Atmospheric Research, U. C. f. A. R., NCAR Global, 2-hourly Ground-Based GPS Precipitable Water, available at: http://rda.ucar.edu/datasets/ ds721.1/ (last access: 7 July 2016), 2011.

Gaffen, D. J. and Elliott, W. P.: Column Water Vapor Content in Clear and Cloudy Skies, J. Climate, 6, 2278-2287, doi:10.1175/1520-0442(1993)006<2278:CWVCIC>2.0.CO;2, 1993.

Gao, B.-C. and Kaufman, Y. J.: Water vapor retrievals using Moderate Resolution Imaging Spectroradiometer (MODIS) near-infrared channels, J. Geophys. Res.-Atmos., 108, 4389, doi:10.1117/12.154909, 2003.

Li, G., Kimura, F., Sato, T., and Huang, D.: A composite analysis of diurnal cycle of GPS precipitable water vapor in central Japan during Calm Summer Days, Theor. Appl. Climatol., 92, 15-29, doi:10.1007/s00704-006-0293-x, 2007.

Lindstrot, R., Preusker, R., Diedrich, H., Doppler, L., Bennartz, R., and Fischer, J.: 1D-Var retrieval of daytime total columnar water vapour from MERIS measurements, Atmos. Meas. Tech., 5, 631646, doi:10.5194/amt-5-631-2012, 2012.

Lindstrot, R., Stengel, M., Schröder, M., Fischer, J., Preusker, R., Schneider, N., Steenbergen, T., and Bojkov, B. R.: A global climatology of total columnar water vapour from SSM/I and MERIS, Earth Syst. Sci. Data, 6, 221-233, doi:10.5194/essd-6221-2014, 2014

Ning, T., Wang, J., Elgered, G., Dick, G., Wickert, J., Bradke, M., Sommer, M., Querel, R., and Smale, D.: The uncertainty of the atmospheric integrated water vapour estimated from GNSS observations, Atmos. Meas. Tech., 9, 79-92, doi:10.5194/amt-979-2016, 2016.

Ortiz de Galisteo, J. P., Cachorro, V., Toledano, C., Torres, B., Laulainen, N., Bennouna, Y., and de Frutos, A.: Diurnal cycle of precipitable water vapor over Spain, Q. J. Roy. Meteor. Soc., 137, 948-958, doi:10.1002/qj.811, 2011. 
Radhakrishna, B., Fabry, F., Braun, J. J., and Hove, T. V.: Precipitable Water from GPS over the Continental United States: Diurnal Cycle, Intercomparisons with NARR, and Link with Convective Initiation, J. Climate, 28, 2584-2599, doi:10.1175/jcli-d-1400366.1, 2015.

Seidel, D. J., Berger, F. H., Immler, F., Sommer, M., Vömel, H., Diamond, H. J., Dykema, J., Goodrich, D., Murray, W., Peterson, T., Sisterson, D., Thorne, P., and Wang, J.: Reference Upper-Air Observations for Climate: Rationale, Progress, and Plans, B. Am. Meteorol. Soc., 90, 361-369, doi:10.1175/2008bams2540.1, 2009.

Trenberth, K. E.: Atmospheric Moisture Recycling: Role of Advection and Local Evaporation, J. Climate, 12, 1368-1381, 1999.
Turner, D. D., Clough, S. A., Liljegren, J. C., Clothiaux, E. E., Cady-Pereira, K. E., and Gaustad, K. L.: Retrieving Liquid Water Path and Precipitable Water Vapor From the Atmospheric Radiation Measurement (ARM) Microwave Radiometers, IEEE T. Geosci. Remote Sens., 45, 3680-3690, doi:10.1109/TGRS.2007.903703, 2007.

Wang, J., Zhang, L., Dai, A., van Hove, T., and van Baelen, J.: A near-global, 2-hourly data set of atmospheric precipitable water from ground-based GPS measurements, J. Geophys. Res.Atmos., 112, D11107, doi:10.1029/2006JD007529, 2007. 